\title{
Express method for determining of organic substances matter in the production water of energy-technological complexes of thermal power plant - petrochemical enterprise
}

\author{
A. A. Filimonova ${ }^{1}$, N. D. Chichirova ${ }^{1}, A$. A. Chichirov $^{1, *}$, and A. A. Batalova ${ }^{1}$ \\ ${ }^{1}$ Kazan State Power Engineering University, Kazan, Russia
}

\begin{abstract}
For a quantitative analysis of the organic matter content in the production waters of the energytechnological complexes of the Thermal Power Plant - petrochemical enterprise, a simple, effective, affordable and very fast method was developed. Its essence is to determine the optical density at a $400 \mathrm{~nm}$ wavelength on a device such as a colorimeter. The correlation with the permanganate oxidation method is 98-99\%. According to the presented method, the quantitative composition of organic substances in the alkaline spent regeneration solution of anion-exchange filters of the Thermal Power Plant (TPP) water treatment plant and in the return condensate from petrochemical enterprise was determined. For each water type, its own calibration schedule was constructed due to significant differences in the qualitative composition of organic impurities.
\end{abstract}

\section{Introduction}

The organic matter content in natural water in qualitative and quantitative composition is many times higher than the inorganic content. Organic matter is detected in all water types of thermal power plants and in some cases in concentrations significantly higher than recommended $[1,2]$. However, until recently, their impact on the processes associated with the operation of the Thermal Power Plant (TPP) coolant has not been given due attention [3]. Such inattention was associated with the general opinion about the organic matter insignificant effect on the thermal equipment operation. This situation has radically changed when reports on emergencies began to appear in the literature, leading to serious power equipment damage caused by proven facts of organic matter large amounts in the feedwater path [4, 5]. All types of feedwater for total organic carbon have been subjected to particularly strict control in connection with the widespread commissioning of combined-cycle plants with waste-heat boilers [6, 7].

We encountered a negative effect of organic substances during the test on the electrochemical separation of an alkaline waste regeneration solution (AWRS) of anion-exchange filters. During the operation of an experimental electromembrane installation, the fact of organic matter transfer from highly contaminated dialysate to an alkaline concentrate was established as a side effect. In addition, the adverse effect of organic substances on the electrical conductivity of membranes during prolonged exposure has been found.

It was previously shown [8] that organic substances in alkaline spent regeneration solution are represented almost exclusively by humus substances - polymeric substances of complex composition of the natural origin. The establishment of the full structural formula of humic substances was not carried out $[9,10]$. Only the determination of humic matter structure fragments and the subsequent recount to total organic carbon is possible.

The organic matter content in the production waters of energy enterprises is judged by the indirect method results. The TPP uses a regular method for permanganate oxidation (PO) determining of water. In addition, the method is indirect, it is long and laborious. For the analysis of deeply purified water by the organic component, total organic carbon analyzers are used. The total organic carbon analysis is based on the destruction of all organic substances in the test solution, followed by detection of released carbon monoxide. This method is currently considered the most accurate and perfect, but also the most expensive $[11,12]$.

In addition, in the works performed in the laboratory and at operating TPP, the content of organic impurities is monitored by the results of conductometric and optical measurements. Thus, some authors propose to evaluate the organic matter content by the value of electrical conductivity $(\chi)$ in various types of deeply purified water [13], or by the value of $\mathrm{pH}$ [14]. It should be noted that impurities present in water have a multifactorial effect on $\chi$ and $\mathrm{pH}$; therefore, these methods are not informative. In [15] an inversely proportional relationship between the content of total organic carbon and the light transmission at $\lambda=210-254 \mathrm{~nm}$ for the untreated water was shown. At the same time, correlation with $\mathrm{PO}$ was not identified, which, according to the authors, is due to the inability of the PO method to

*Corresponding author: aachichirova@mail.ru 
adequately evaluate the organic impurities in the demineralized water.

In this regard, there is an urgent need to develop a rapid method for organic matter content determining in the production waters of thermal power plants.

Humic substances (HS) in water give a color ranging from pale yellow to wine-red, depending on the species, origin and concentration. The semi-quantitative method for their content determination is based on this. Since chromaticity very much depends on the type and origin of HS, the use of a few literature data is difficult.

\section{Methods}

We conducted our own studies of the organic fraction, which is present in alkaline spent regeneration solutions (AWRS) of a water treatment plant anion-exchange filters. The studies included the isolation of organic substances from industrial waters, the model solution preparation, the electronic spectra recording in the visible region, and the calibration curves construction. According to the research results, the optimal wavelength was determined at which the comparison of optical density and PO was performed.

\section{Results}

Figure 1 shows the dependence of optical density at different wavelengths on the mass concentration of humic substances in model aqueous solutions. It may be noted linear dependence in the range of $350-400 \mathrm{~nm}$.

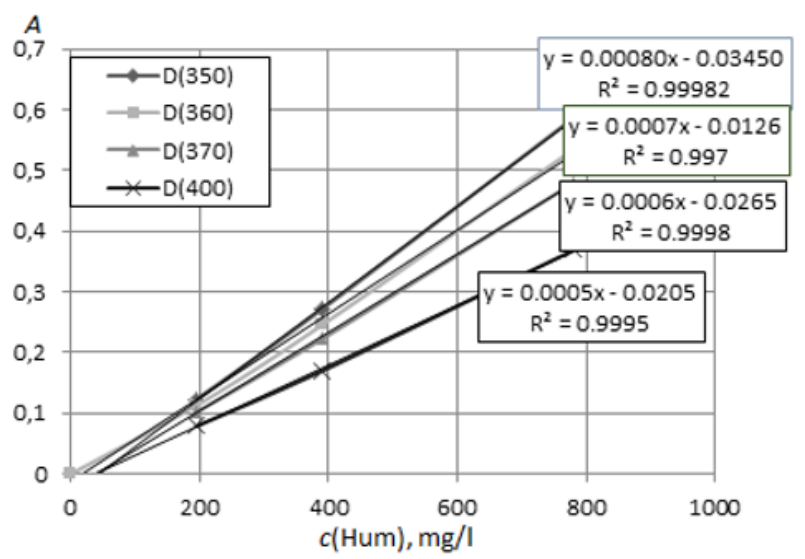

Fig. 1. The dependence of optical density (A) on the concentration of humic substances in aqueous solutions. D wavelength. Cuvette thickness $-1 \mathrm{~mm}$.

On alkaline spent regeneration solutions of the water treatment plant anion-exchange filters, measurements of the optical density and PO were carried out in parallel. At high values of $\mathrm{A}$, the solutions were diluted with distilled water in order to remain within A not more than 1.5. According to the obtained data, calibration curves were constructed at $\lambda=350 \mathrm{~nm}$ and $400 \mathrm{~nm}$ (Figures 2, 3).

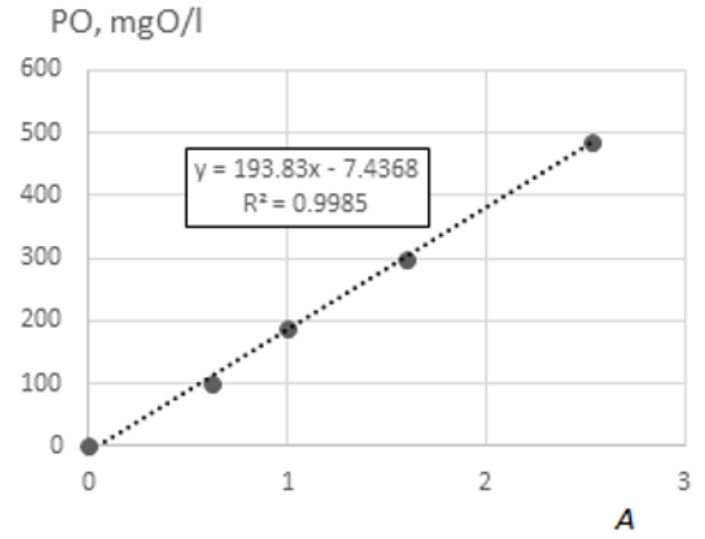

Fig. 2. Calibration curve for PO determination by optical density at $\lambda=400 \mathrm{~nm}$ in the AWRS of the TPP water treatment plant. The cuvette thickness is $50 \mathrm{~mm}$.

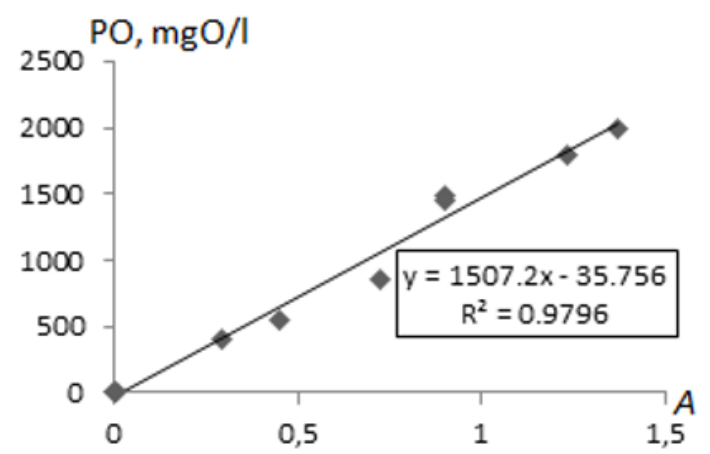

Fig. 3. Calibration curve for PO determination by optical density at $\lambda=350 \mathrm{~nm}$ in the AWRS of the TPP water treatment plant. The cuvette thickness is $1 \mathrm{~mm}$.

Thus, a method was developed for the rapid analysis of alkaline washing waters after the regeneration of anionite filters for the humic organic matter content. The technique is based on optical density measuring of solutions in the spectrum visible part in the wavelength range of $350-400 \mathrm{~nm}$. There is a high degree of correlation between the optical density and water permanganate oxidation $\left(\mathrm{R}^{2}>0.998\right)$, which shows agreement with the Bouguer-Lambert-Beer law. The wavelength of $400 \mathrm{~nm}$ is chosen, as it gives the most reproducible results. According to the experimental data, calibration curves were constructed, showing linearity in the range of $0-5000 \mathrm{mgO}_{2} / 1$.

The method allows you to quickly assess the permanganate oxidation in the range of $0-2500 \mathrm{mgO}_{2} / 1$. The time for carrying out the optical measurement does not exceed 5 minutes, which makes it possible to attribute it to the express method. For analysis, you can use a simple and affordable instrument - colorimeter. Analysis accuracy is $\pm 2 \mathrm{rel}$. \% for permanganate oxidation.

The next step was the approbation of the presented method on waters containing a different type of organic matter, namely, small organic molecules that are petrochemical by-products. For these purposes, samples of return condensate were taken from the factories for the production of synthetic rubber, styrene and polyester resins. 
The chromatography gas-liquid results of the condensate are presented in tables 1,2 .

Table 1. The chromatographic results of condensate from synthetic rubber plants.

\begin{tabular}{|c|c|}
\hline Component name & Concentration, $\mathrm{mg} / \mathrm{dm}^{3}$ \\
\hline isoprene & 2.5 \\
\hline methanol & 21.1 \\
\hline acetone & 15.5 \\
\hline acetaldehyde & 1.0 \\
\hline isopropanol & 0.5 \\
\hline ethanol & 0.6 \\
\hline
\end{tabular}

Presented in table 1 data indicates that condensate from synthetic rubber plants has been contaminated with hydrocarbons from isoamylenes dehydrogenation production.

Table 2. The chromatographic results of condensate from the styrene and polyester resins plant.

\begin{tabular}{|c|c|}
\hline Component name & Concentration, $\mathrm{mg} / \mathrm{dm}^{3}$ \\
\hline allyl alcohol & 3.36 \\
\hline styrene & 10.49 \\
\hline phenol & 1.7 \\
\hline
\end{tabular}

From the table 2 data it can be seen that a large amount of styrene was detected $\left(10.49 \mathrm{mg} / \mathrm{dm}^{3}\right)$.

The next important difference between the return condensate samples and the samples of AWRS was the color, or rather its absence. The sample from styrene and polyester resin plant had a pale yellow shade and full transparency, and the sample from the synthetic rubber plant was completely colorless and transparent.

No less significant than the color index is the concentration of organic substances in samples of the return condensate compared with samples of anionite filter washing regeneration solutions, an average of 20 $\mathrm{mg} / \mathrm{dm}^{3}$ vs. $200 \mathrm{mg} / \mathrm{dm}^{3}$, respectively. Such a relatively small amount of "organics" in practically colorless samples of return condensate questioned the possibility of the colorimetric organic matter determination in them. In order to compare the results, measurements of optical density and PO were carried out in parallel. According to the obtained data, calibration curves were constructed for samples of the return condensate from the synthetic rubber (Figure 4) and styrene and polyester resin plants (Figure 5).

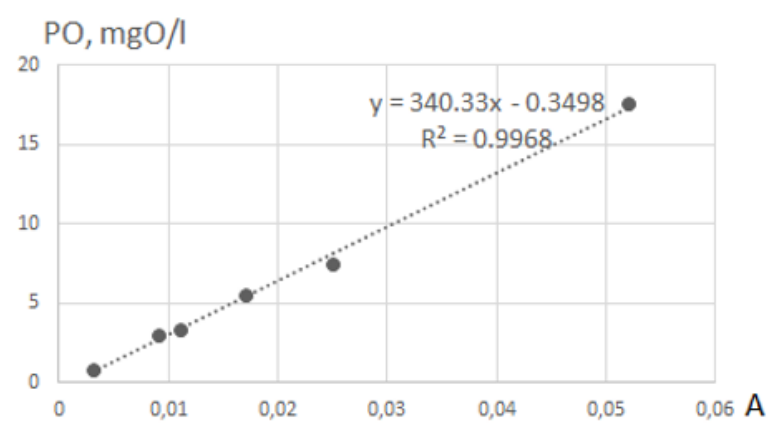

Fig. 4. Calibration curve for PO determination by optical density at $\lambda=400 \mathrm{~nm}$ in return condensate samples from the synthetic rubber plant. The cuvette thickness is $50 \mathrm{~mm}$.

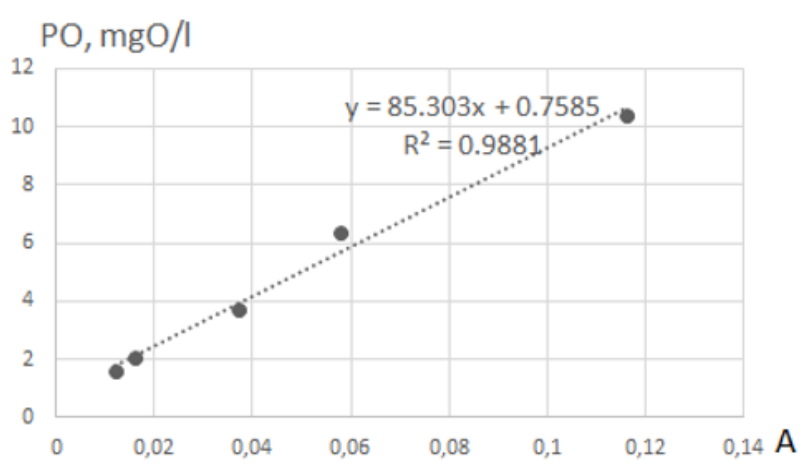

Fig. 5. Calibration curve for PO determining by optical density at $\lambda=400 \mathrm{~nm}$ in return condensate samples from the styrene and polyester resin plant. The cuvette thickness is $50 \mathrm{~mm}$.

In both cases, there is a high degree of correlation between optical density and permanganate oxidation of water $\left(\mathrm{R}^{2}>0.98\right)$. Consequently, by constructing a calibration graph, we are able to significantly speed up the determination of the total organic matter content in the return condensate, eliminating from it such a long and laborious method as permanganate oxidation and will be limited only to measuring the optical density of the sample on a colorimeter.

The results of the relationship of optical density at a wavelength of $400 \mathrm{~nm}$ and permanganate oxidation testify the possibility of using the proposed colorimetric method in those types of water in which it is possible to interpret the results of permanganate oxidation method, regardless of the water color and the organic matter concentration.

\section{Discussion}

A quantitative rapid method has been developed for determination the organic matter content in the production waters of energy-technological complexes of TPP-Petrochemical Plant. The method allows to evaluate the permanganate oxidability in the range of $0-2500$ $\mathrm{mgO}_{2} / 1$. For analysis, you can use a simple and affordable instrument - colorimeter. Analysis accuracy is \pm 2 rel. \% for the permanganate oxidability. The highest correlation is obtained at a wavelength of $400 \mathrm{~nm}$.

\section{References}

[1] G.V. Slavinskaya, V.F. Selemenev, Organic Substances As a Factor Complicating The Conditioning Of Industrial And Drinking Water Sorption And Chromatographic Processes 2, 297-302 (2007)

[2] A.S. Michal, Minimizing levels of Volatile Organic Acids and Carbon Dioxide in Steam Water circuits : Proc. Int. Conf. Interaction of Organic and Organic Cycle Treatment Chemicals with Water Steam (Stuttgart) 115-119 (2005)

[3] B.M. Larin, A.B. Larin, S.Yu. Suslov, A.V. Kirilina, Rationing Of The Quality Of The Water Coolant At The Russian Thermal Power Plants Thermal Power 4, 79-84 (2017) 
[4] O.I. Martynova, T.N. Petrova, O.S. Ermakov, A.A. Zotov, The Behavior Of The Products Of Thermolysis Of Organic Substances In The Two-Phase Region: Boiling Water - Equilibrium Saturated Steam Thermal Power 6, 8-11 (1997)

[5] V.A. Korovin, S.D. Shcherbina, Potentially Hazardous Substances For Equipment Of Power Plants Thermal Engineering 2, 48-50 (1999)

[6] Rules Of Technical Operation Of Power Plants And Networks Of The Russian Federation (Saint Petersburg: Dean) 336 (2004)

[7] Organization Standard 70238424.27.100.013Water Treatment Plants And Water-Chemical Regime Of Thermal Power Plants Terms Of Creation. Standards And Requirements (Moscow) (2009)

[8] A.A. Chichirov, N.D. Chichirova, A.A. Filimonova, A.A. Gafiatullina, Qualitative And Quantitative Analysis Of Organic Impurities In The Feedwater Of The Recovery Boiler Thermal Engineering 3, 168-173 (2018)

[9] S.Yu. Smirnova, I.Yu. Tikhomirova, Using The Optical Properties Of Humic Acids To Study Their Composition By The Method Of IR-Spectroscopy Actual Problems Of Biological And Chemical Ecology; Materials Of The V International Scientific Practical Conference 286-291(2016)

[10] R.M. Silverstein, F.X. Webster, D.J. Kiemle, Spectrometric Identification Of Organic Compounds (US) (2005)

[11] J.D. Ronald, D.G. Richard, Pulsed-flow total organic carbon analyzer Patent US6723565B2 (2001)

[12] V.N. Scherbakov, M.S. Poleshkin, V.I. Antonenko, Improvement Of Methods And Devices For Monitoring The Content Of Organic Impurities In The Coolant At Thermal Power Plants And Thermal Power Plants Bulletin Of The Don State Technical University 4(91), 50-60 (2017)

[13] B.S. Fedoseev, S.Yu. Suslov, V.A. Sivovolov, A.M. Kozlov, On the Possibility of Measuring the Salinity of Organic Compounds in the Steam-Water Steam of a TPP Energetik 10, 26-28 (2004)

[14] V.A. Ryzhenkov, S.I. Pogorelov, N.A. Naryadkina, E.V. Ezhov, O.V. Kalakutskaya, D.A. Tarasenko, Operational determination of organic compounds in the working and technological environments of thermal power plants Energy security and energy saving 2, 34-39 (2012)

[15] N.A. Belokonova, The Effect Of Organic Impurities On Water Purification Processes In Heat And Power Engineering (Ekaterinburg: Azhur) 104 (2008) 